Vol. 6, No. 2, 2009, p. 173-202

ISSN online: $1807-1775$

DOI: $10.4301 / S 1807-17752009000200003$

\title{
OUTSOURCING DE TI E REDEFINIÇÃO DO PAPEL DA SUBSIDIÁRIA: UM ESTUDO COMPARATIVO ENTRE AS SUBSIDIÁRIAS BRASILEIRA E INDIANA DE UMA MULTINACIONAL AMERICANA
}

\author{
IT OUTSOURCING AND REDEFINITION OF THE SUBSIDIARY ROLE: \\ A COMPARATIVE STUDY BETWEEN THE BRAZILIAN AND THE \\ INDIAN SUBSIDIARIES OF AN AMERICAN MULTINATIONAL
}

\author{
Marco Aurélio da Silva \\ PUC Minas - Fundação Dom Cabral, Brasil \\ Roberto Gonzalez Duarte \\ Universidade Federal de Minas Gerais, Brasil \\ José Márcio de Castro \\ PUC Minas - Fundação Dom Cabral, Brasil \\ Aristides Rocha Araújo \\ PUC Minas - Fundação Dom Cabral, Brasil
}

\begin{abstract}
Global outsourcing, also known as offshoring, has become a major phenomenon in the IT industry. Responsibilities have been transferred to IT suppliers worldwide. A key element of this strategic change occurred in the IT sector is the growing importance of emerging economies, such as Brazil and India. A stream of the literature on international business has analysed which factors may affect the evolution of a subsidiary within a multinational. This paper aims to analyse how exporting outsourcing IT services can redefine the role of a subsidiary within a corporation, hence change its strategic relevance. An empirical research compared the offshoring activities of two subsidiaries -Brazilian and Indian - of an American IT multinational, focusing in particular on how subsidiary choice, head office assignment and environment determinism factors interact to each other in order to determine the evolution and the role of each subsidiary. The results have demonstrated that the Indian subsidiary trajectory was essentially determined by the development of its resources, innovation, governmental support and entrepreneurship. The Brazilian subsidiary trajectory in turn was mostly influenced by head office assignment and subsidiary performance.
\end{abstract}

Recebido em/Manuscript first received: 08/02/2009 Aprovado em/Manuscript accepted: 06/06/2009 Endereço para correspondência/ Address for correspondence

Marco Aurélio da Silva , Pontifícia Universidade Católica-Fundação Dom Cabral, Minas Gerais- BrasilE-mail: msta@ig.com.br

Roberto Gonzalez Duarte, Universidade Federal de Minas Gerais, Minas Gerais- Brasil- E-mail: robertoduarte@face.ufmg.br

José Márcio de Castro, Pontifícia Universidade Católica, Minas Gerais, Brasil- E-mail: josemarcio@pucminas.br

Aristides Rocha Araújo, Pontifícia Universidade Católica- Minas Gerais- Brasil- E-mail: aristidesaraujo@hotmail.com

ISSN online: 1807-1775

Publicado por/Published by: TECSI FEA USP - 2009 
A comparative analysis between the two cases has demonstrated how these aspects have altogether determined why these subsidiaries have evolved differently from each other. Most importantly, this paper argues that, in addition to these three factors, management capacity and subsidiary leadership are critical elements to understand the evolution of a multinational subsidiary trajectory.

Keywords: IT; outsourcing, offshoring; strategic relevance; multinational subsidiaries

\section{RESUMO}

A exportacão de outsourcing de TI, também conhecida como offshoring, tem se tornado um dos principais fenômenos no setor de TI. Responsabilidades têm sido transferidas para fornecedores de TI em todo o mundo. Um aspecto chave desse fenômeno é a crescente importância que economias emergentes, tais como, Brasil e Índia, vêm assumindo como provedores de offshoring de TI. Tendo como referência a literatura sobre evolução de subsidiárias de multinacionais, este trabalho tem como objetivo analisar como a exportação de serviços terceirizados de TI pode redefinir o papel de uma subsidiária dentro de uma corporação e, assim, alterar a sua relevância estratégica. Uma investigação empírica compara o desenvolvimento das atividades de offshoring de duas subsidiárias - brasileira e indiana - de uma multinacional americana de TI e, mais especificamente, como tais atividades têm contribuído para redefinir o papel e a relevância estratégica de cada uma delas. Em particular, a investigação empírica analisou a forma como três fatores - escolhas da subsidiária, determinações da matriz e determinismo ambiental - interagem determinando a evolução e o papel das subsidiárias. Os resultados demonstraram que a trajetória da subsidiária indiana foi essencialmente determinada pelo desenvolvimento dos seus recursos, a inovação, o apoio governamental e empresarial. A trajetória da subsidiária brasileira, por sua vez, foi principalmente influenciada pelas determinações da matriz e desempenho da subsidiária. Argumenta-se, por fim, que, além desses três fatores, a capacidade de gestão e liderança da subsidiária são elementos críticos para compreender a evolução da trajetória de uma subsidiária multinacional.

Palavras-Chave: TI; outsourcing; offshoring; relevância estratégica; subsidiárias de multinacionais

\section{Os autores agradecem a Felipe Mendes Borini os valiosos comentários e sugestões}


Outsourcing de TI e redefinição do papel da subsidiária: um estudo comparativo entre as subsidiárias brasileira e indiana de uma multinacional americana

\section{INTRODUÇÃO}

A atividade de terceirização ou outsourcing ${ }^{1}$ de tecnologia da informação (TI) tem apresentado taxas significativas de crescimento no segmento ${ }^{2}$ de serviços de TI. Isso é válido tanto para o mercado brasileiro (IDC, 2005) quanto para o mercado global (GARTNER, 2005). Em termos globais, o Gartner Group (2005), um dos principais grupos de consultoria e pesquisa na área de TI no mundo, prevê um crescimento mundial anual de 7,3\% (13\% para a América Latina) para os serviços de outsourcing no período entre 2004 e 2009. E espera que essa taxa de crescimento se mantenha até 2012. Em 2008, os serviços de TI representaram grande parte dos contratos de outsourcing, aproximadamente 70\% (GARTNER, 2008). No Brasil, o segmento de serviços de TI movimentou aproximadamente 4 bilhões de reais em 2004, um crescimento de 16,58\% em relação ao ano anterior (IDC, 2005). Segundo o Gartner (2008), o Brasil deverá ser um player importante no fornecimento de serviços offshore e nearshore.

Além de ser a atividade que apresenta a maior taxa de crescimento no segmento de serviço de TI, o outsourcing passa por um momento de transformação. O Gartner Group (2005) verifica duas grandes tendências no outsourcing: (i) a terceirização transfronteira de TI denominada global delivery ou offshoring e (ii) a padronização dos serviços, ou seja, a forma de prover os serviços está cada vez mais homogeneizada (mesmos processos, mesmas ferramentas e mesma gestão).

O offshoring tem se tornado um dos principais fenômenos da indústria de TI. (Carmel; Tjia (2005). Vários fatores têm impulsionado a expansão internacional desse tipo de terceirização: (i) existência de mão-de-obra qualificada e de baixo custo em alguns países em desenvolvimento, como Índia; (ii) movimento de desregulamentação em alguns países resultando em acordos comerciais e/ou eliminação de tarifas; (iii) aumento de velocidade dos links de comunicação; e, (iv) a homogeneização das características da demanda e fornecimento de serviços entre países. (Carmel; TJIA, 2005; Sahay; Nicholson; Krishna, 2003).

Atraídas pela estrutura de baixo custo e pela possibilidade de acessar um pool de recursos globais, empresas multinacionais (EMNs) começam a usufruir as vantagens do offshoring, tanto por meio de suas próprias subsidiárias localizadas em diferentes países, quanto por meio de terceiros. O offshoring tem representado, na realidade, uma

\footnotetext{
${ }^{1}$ Outsourcing de TI pode ser definido como a contratação de uma organização externa especializada para fornecer serviços de TI. Isso ocorre quando a empresa não quer utilizar seus recursos internos para operar e/ou implementar seu próprio setor de TI. Neste artigo, os termos outsourcing e terceirização são utilizados de forma intercambiável.

${ }^{2}$ O setor de TI pode ser basicamente dividido em três principais segmentos: (i) hardware; (ii) software; e (iii) serviços de TI. No segmento serviços de TI, entre as diversas categorias ou tipos de serviços que o compõem estão: (i) outsourcing; (ii) consultoria; (iii) integração e desenvolvimento; (iv) suporte e treinamento. O serviço de outsourcing por sua vez pode ser subdividido em: (i) outsourcing de aplicações de software (desenvolvimento e manutenção); (ii) outsourcing de infraestrutura de TI (gerenciamento de máquinas, servidores) e (iii) outsourcing de processos de negócios altamente dependentes de TI, tais como compras, Recursos Humanos, entre outros.
} 
oportunidade para muitas subsidiárias aumentarem sua relevância estratégica e/ou redefinir o seu papel dentro da corporação. (Carmel; Tjia, 2005). Algumas subsidiárias, por exemplo, procuram, por meio da inovação, aumentar sua responsabilidade internacional (Bartlett; Ghoshal, 1989; Gupta; Govindarajan, 1991; Jarillo; Martinez, 1990).

O estudo das subsidiárias de EMNs é recente. As primeiras pesquisas, desenvolvidas ainda na década de 1980, focalizaram, sobretudo, os papéis exercidos pelas subsidiárias ou, mais precisamente, a sua importância para a matriz. Uma abordagem mais recente tem buscado analisar como esse papel pode se transformar ao longo do tempo e investigar os fatores que determinam essa transformação, ou seja, o desenvolvimento das subsidiárias. (Birkinshaw, 2001). Como nas últimas duas décadas, as EMNs tendem a integrar suas funções dispersas globalmente, (Birkinshaw, 1996), ou seja, a subsidiária seria parte da estrutura de um negócio global e integrado. Isso implica a redefinição do próprio conceito de subsidiária (Birkinshaw, 2001).

Sendo assim, este artigo tem como propósito analisar como a exportação de outsourcing pode modificar a relevância estratégica e redefinir o papel das subsidiárias. Mais especificamente, o artigo compara as trajetórias de diferentes subsidiárias e identifica as características - internas e externas - determinantes da evolução de cada uma delas. Para tanto, serão comparadas as trajetórias de duas subsidiárias - brasileira e indiana - de uma EMN americana do setor de TI.

Para além dessa introdução, o artigo discute, no referencial teórico, a partir da literatura sobre evolução e desenvolvimento de subsidiárias, como o offshoring pode contribuir para a redefinição do papel de uma subsidiária. Subsequentemente, apresentase a metodologia utilizada na pesquisa empírica. Em seguida, apresentam-se os resultados da pesquisa. Por último, são discutidas, respectivamente, os casos estudados e as considerações finais, em que se ressaltam, principalmente, as implicações para a literatura, as limitações da pesquisa e sugestões para pesquisas futuras.

\section{REFERENCIAL TEÓRICO}

\section{1 - O outsourcing de TI}

Se uma empresa não deseja utilizar seus recursos internos para operar ou implementar sua área de TI, ela pode contratar uma organização externa para fornecer esse serviço. Esse processo é conhecido como terceirização de TI (IT outsourcing). Tal processo pode envolver as operações de gerência de infraestrutura de TI - o centro de computação e as redes de telecomunicações - o desenvolvimento e a gerência das aplicações e, mais recentemente, os processos de negócio dependentes de TI. ${ }^{3}$

\footnotetext{
${ }^{3}$ A terceirização de processos de negócios, também denominado Business Process Outsourcing (BPO), se refere a negócios intensivos em fluxos de informações, portanto dependentes de TI, tais como atividades de recursos humanos, folha de pagamento, faturamento, entre outros.
} 
Atualmente, o outsourcing de TI é entendido como parte de uma transformação estratégica da função de TI, em que novas responsabilidades são transferidas para o provedor de serviços. No outsourcing tradicional, a transferência de atividades de TI estava associada à redução direta de custos ou à resolução imediata de um problema, mas no transformational outsourcing, novas responsabilidades são transferidas para o provedor de serviços de TI. (Gottschalk; Solli-Sæther, 2006). Prevê-se, então, que a terceirização terá um efeito ainda maior para as empresas no futuro, pois ela será utilizada para melhorar os processos de negócio dessas empresas e para aumentar sua capacidade de inovação. (Gottschalk; Solli-Sæther, 2006). Outra tendência importante do offshoring será a crescente participação das economias emergentes na globalização do setor de TI (Carmel e Tija, 2005).

As principais forças tecnológicas e econômicas que têm contribuído para o crescimento do offshore são: (i) a globalização do setor de serviços; (ii) a competição entre países para atrair investimento estrangeiro diretos (IDE) e desenvolver seus setores de TI; (iii) o aumento do número de profissionais egressos de universidades e escolas técnicas em países emergentes; (iv) a redução drástica dos custos de comunicação; (v) a comoditização do software por meio da padronização das práticas e ferramentas de desenvolvimento, o que possibilita a "rotinização" e a automatização de algumas atividades; e, (vi) a diferença entre os salários pagos nos países emergentes e nos desenvolvidos (Carmel e Tija, 2005).

Embora a redução de custos seja, atualmente, o principal motivador do offshoring, conforme Corbett (2004), a diferença em termos de salários não deve se manter no mesmo nível para sempre. Pressões por aumento de salários em virtude da demanda por mão-de-obra já ocorrem em alguns países, como a Índia. Sendo assim, o apelo do offshoring permanecerá apenas se este criar valor adicional para as organizações.

\section{2 - O offshoring como meio de redefinição do papel da subsidiária}

Os serviços de offshoring podem ser fornecidos pelas unidades da própria EMN localizadas em países diferentes, ou ainda por outras empresas também localizadas em países diferentes. De acordo com Ferdows (1997), a subsidiária offshore é definida como aquela que produz itens específicos a baixo custo, seguindo métodos preestabelecidos, mas não é inovadora. Tal concepção do offshoring, baseada exclusivamente na redução de custos, desconsidera, por exemplo, a autonomia da subsidiária para definir novos processos e tecnologias e, assim, evoluir em seu papel dentro da corporação. (D’cruz, 1986; White; Pointer, 1984; Birkinshaw; MORRISON, 1995).

O offshoring está, na realidade, alinhado com a necessidade de racionalização, que é consequência da globalização e pode ser utilizado também pelas subsidiárias para 
ir além de seu papel de "contribuidora” especializada. ${ }^{4}$ Krishan (2006) cita o exemplo de subsidiárias indianas, para as quais o offshoring, somado ao seu perfil empreendedor, foi fundamental para que ganhassem mais relevância no contexto da corporação.

Dependendo da evolução da subsidiária, ela pode ser uma contribuidora ou uma líder estratégica (Bartlett; Ghoshal, 1989), uma fonte de recursos valiosos para outras unidades (Gupta; Govindarajan, 1991) ou, então, receber mandatos globais ${ }^{5}$ para desenvolver certos tipos de produtos ou serviços para o mercado global. (D'cruz, 1986; White; Pointer, 1984; Birkinshaw; Morrison, 1995).

A subsidiária pode ainda tornar-se um centro de excelência, definido como uma unidade organizacional contendo um conjunto de competências, que tenham sido explicitamente reconhecidas pela corporação como fonte de criação de valor e sejam utilizadas ou disseminadas para outras unidades da corporação. (Frost, Birkinshaw e Ensign, 2002). Segundo Holm e Pedersen (2000), o centro de excelência não se restringe a um único conhecimento, passível de utilização em determinada contingência, nem a uma responsabilidade geral, tal como produzir e vender, com o propósito de adquirir eficiência e ser um centro em termos de tamanho e volume. Mais do que isso, o centro de excelência mantém um ou mais campos críticos de conhecimento que têm impacto de longo prazo para o desenvolvimento das atividades desenvolvidas em outras unidades da organização. (Holm; Pedersen, 2000). O conceito de centro de excelência difere, assim, do de mandato global, em que a subsidiária detém responsabilidade total sobre certo produto ou segmento de atuação.

A crescente participação da subsidiária contribui para o desenvolvimento de vantagens competitivas para a corporação. Tendo certo grau de liberdade para definir seu próprio futuro, o desafio para a subsidiária é compreender as condições necessárias para desenvolver um conjunto de competências que sejam reconhecidas pela corporação como fonte de criação de valor. (Birkinshaw, Hood; Jonsson, 1998). (Birkinshaw; Hood; Jonsson, 1998).

Embora o offshoring represente uma oportunidade de desenvolvimento para as subsidiárias, apenas recentemente os pesquisadores têm buscado entender como e quais fatores determinam esse desenvolvimento. Após a década de 1980, mais subsidiárias têm mostrado sua capacidade em levar adiante idéias de ponta, em executar trabalhos de pesquisa para a corporação e em tornar-se ativas participantes na formulação e implementação da estratégia da organização. Assim, a geração de vantagens competitivas deixa de ser uma atividade exclusiva da matriz e torna-se uma responsabilidade coletiva de toda a rede corporativa.

$\mathrm{Na}$ literatura, são identificadas três perspectivas sobre a contribuição da subsidiária: (i) determinismo ambiental; (ii) determinação da matriz; e (iii) escolha da

\footnotetext{
${ }^{4}$ Contribuidora especializada refere-se à subsidiária que detém recursos comparativamente superiores àqueles disponíveis em outras unidades da corporação.

${ }^{5}$ De modo geral, as expressões contribuidor especializado, líder estratégico e mandato global são utilizadas em referência às subsidiárias que contribuem - em graus diferenciados - para as vantagens competitivas da corporação (Birkinshaw; Hood; Jonsson, 1998).
} 
Outsourcing de TI e redefinição do papel da subsidiária: um estudo comparativo entre as subsidiárias brasileira e indiana de uma multinacional americana

subsidiária (Birkinshaw; Hood; Jonsson, 1998; Birkinshaw, 2001; Paterson; Brock, 2002). A análise conjunta dessas perspectivas permite que se compreenda como uma subsidiária desenvolve competências que podem redefinir o seu posicionamento no contexto da corporação.

\subsection{1 - Determinismo ambiental}

Tendo como base a teoria da vantagem competitiva das nações (Porter, 1990), a primeira perspectiva - determinismo ambiental - discute a influência do contexto competitivo de cada país para a relevância estratégica da subsidiária. Quanto maior a dinâmica da rivalidade local, das condições dos fatores de produção, das indústrias correlatas e de apoio e da demanda nacional, maior a possibilidade da subsidiária desempenhar um papel de importância estratégica.

Segundo Porter (1990), o governo pode promover e melhorar as condições do ambiente local. Os governos podem, por exemplo, alterar estruturas de taxação, normas regulatórias e acordos que prejudiquem ou favoreçam a operação de subsidiárias. Assim, embora não seja capaz de criar setores competitivos, pois essa é uma tarefa exclusiva das empresas, o governo tem o poder de incentivar ou de impedir o desenvolvimento competitivo da empresa.

Borini, Oliveira e Guevara (2004) argumentam que, com a globalização dos mercados e com o crescimento das multinacionais (MNEs), os governos têm promovido políticas e ações com o objetivo de influenciar as estruturas setoriais e, consequentemente, influenciar a competitividade das empresas desses setores. A intervenção governamental pode, então, ser determinante para modificar as estratégias de competidores globais, bem como a evolução de determinados setores e a rivalidade entre empresas. Os autores argumentam que a competitividade das subsidiárias deve ser considerada em um contexto de competição global, e não apenas de competição local, como sugere Porter (1990). Assim, um fator para se compreender a relevância estratégica de uma subsidiária seria, então, o grau de globalização da indústria (Birkinshaw; Hood; Jonsson, 1998).

Um aspecto-chave do contexto local é o ambiente institucional do país. A legislação pode impedir ou permitir, por exemplo, o acesso da MNE aos recursos de um país. Uma legislação mais restritiva ao capital estrangeiro pode, às vezes, dificultar o acesso das MNEs a determinados recursos e, consequentemente, à integração com outras unidades da corporação. (Borini; Oliveira; Guevara, 2004).

Makino, Isobe e Chan (2004) examinam os efeitos do ambiente local para o desempenho das subsidiárias, relativamente a outros efeitos como indústria, que relaciona a variação de desempenho de subsidiárias em diferentes indústrias, e corporação, que relaciona a variação de desempenho de subsidiárias em diferentes corporações. Segundo esses autores, a variação de desempenho das subsidiárias deve-se às diferenças entre os atributos da corporação ou do país em que elas atuam. Do ponto de vista do fator ambiente local, o desempenho da subsidiária é influenciado não somente pelos atributos do país, mas também por suas instituições. Estas são definidas 
como as regras dominantes em uma sociedade ou país, incluindo as regras formais (políticas, direito de propriedade e contratos) e as informais (convenções, normas de comportamento e regras de conduta). O efeito das instituições varia entre países, pois desenvolvem-se de maneira independente em cada nação. Assim, as subsidiárias podem ter um desempenho superior combinando as vantagens específicas da corporação (produtos, tecnologias, processos) com as vantagens específicas do país (capital, terra, trabalho) e com as vantagens específicas da indústria local.

\subsection{2 - Determinação da matriz}

A segunda perspectiva argumenta que a definição do papel da subsidiária é de responsabilidade da matriz. As determinações estratégicas da matriz em termos de estrutura, controles e autonomia, entre outros, definem a importância da subsidiária.

Para Birkinshaw, Hood e Jonsson (1998), a maioria dos estudos dessa abordagem concentra-se no aspecto estrutural, tais como mecanismos de controle e coordenação, que podem ser usados pela corporação para definir o papel da subsidiária. Birkinshaw (1999) analisa três dimensões desses mecanismos de controle: (i) centralização do processo decisório, ou seja, a matriz assume as decisões que afetam as atividades da subsidiária; (ii) credibilidade, que é o nível de conhecimento e de confiança da matriz na capacidade da subsidiária; e (iii) comunicação corporaçãosubsidiária, representada pelas interações pessoais entre os executivos da matriz e os executivos da subsidiária. Dessa forma, se não há credibilidade, se as decisões são centralizadas e se inexiste comunicação entre os dois lados, é improvável que a subsidiária desenvolva iniciativas que aumentem a importância de seu papel em relação ao conjunto da corporação.

Um dos aspectos essenciais nessa perspectiva é a questão da autonomia. Varblane, Männik e Hannula (2004) sugerem que a associação entre desempenho e autonomia depende do tipo de autonomia. Como o grau de autonomia pode variar entre as áreas funcionais, os autores concluem que essa variação pode ter impactos distintos no desempenho das subsidiárias. Birkinshaw, Hood e Jonsson (1998), por sua vez, demonstram que a iniciativa na subsidiária está associada a um alto grau de autonomia, além de alto grau de comunicação entre matriz e subsidiária, e alta integração normativa. Eles ponderam, contudo, que o excesso de autonomia pode resultar na falta de integração, o que limita as chances de a subsidiária ser reconhecida por seus recursos especializados ${ }^{6}$.

Frost, Birkinshaw e Ensign (2002) argumentam que, se por um lado, a autonomia é necessária para a criação de competências, permitindo, eventualmente, à subsidiária tornar-se, por exemplo, um centro de excelência, por outro, ela é forçada a abrir mão de certa autonomia na medida em que precisa se inserir na rede de subsidiárias da corporação (integrando inovação, produção e distribuição). Frost,

\footnotetext{
${ }^{6}$ Birkinshaw (2001) diz que o recurso de uma subsidiária é especializado quando ele é superior aos disponíveis em outras unidades da corporação.
} 
Outsourcing de TI e redefinição do papel da subsidiária: um estudo comparativo entre as subsidiárias brasileira e indiana de uma multinacional americana

Birkinshaw e Ensign (2002) sugerem, então, um processo evolutivo em que mais investimento significa mais responsabilidade e mais responsabilidade significa menos autonomia para agir com independência.

Assim, a autonomia pode ser um determinante do desenvolvimento de competências e de iniciativas (Birkinshaw; Hood, 1998). Mas é preciso observar que essa autonomia deve estar acompanhada da existência de recursos especializados, da integração normativa e de uma intensa comunicação entre as subsidiárias e entre as subsidiárias e a matriz. A integração da atividade de uma subsidiária com o restante da corporação é essencial para o alinhamento estratégico da subsidiária com os processos, as atividades e as diretrizes estratégicas tanto da matriz quanto das outras subsidiárias. Birkinshaw e Hood (1998) sugerem que a integração entre a matriz e as subsidiárias tem um forte impacto nos processos de construção das competências dessas subsidiárias. Note-se ainda que iniciativas das subsidiárias são avaliadas pela qualidade da integração ou relação (em termos de confiança, credibilidade e conhecimento entre as subsidiárias e entre a subsidiária e a matriz) do que apenas pelos méritos técnicos dessas iniciativas. Na relação matriz-subsidiária, quanto mais fortes a confiança, a credibilidade e o conhecimento, menores serão as chances de "desinvestimento" na subsidiária. A decisão de desinvestimento se torna tanto mais difícil quanto mais estreitos os vínculos entre matriz e subsidiárias estiverem os negócios, os contatos e as relações de trabalho.

\subsection{3 - Escolha da subsidiária}

A terceira perspectiva propõe que o papel da subsidiária é determinado por ela própria. A subsidiária teria mais capacidade que a matriz para entender a complexidade e as oportunidades do local em que opera. Dessa forma, os recursos e as capacidades ${ }^{7}$ da subsidiária, as aspirações dos seus executivos e a iniciativa dos empregados determinam o seu papel. (Birkinshaw; Hood; Jonsson, 1998).

De acordo com Birkinshaw, Hood e Jonsson (1998), as vantagens de uma multinacional podem ser: (i) locais (a força de vendas, por exemplo), quando o valor do recurso está limitado à região em que a subsidiária atua e (ii) não locais (por exemplo, a área de P\&D), que podem ser potencialmente utilizados pelas subsidiárias localizadas em outras regiões. Rugman e Verbeke (2001) argumentam que, além dessas duas, devese levar em conta uma terceira: vantagem específica da subsidiária. Segundo esses autores, as vantagens não locais tem duas características: (i) podem ser exploradas globalmente e (ii) são relativamente simples de serem difundida internamente. As vantagens locais, por sua vez, tem características inversas: (i) tem o caráter da responsividade local e (ii) é difícil difundí-las internamente. A terceira vantagem específica da subsidiária - combina os benefícios da exploração global do conhecimento com a dificuldade de sua difusão interna.

\footnotetext{
${ }^{7}$ Birkinshaw (2001) define recursos como o estoque de fatores disponíveis controlados pela subsidiária: matéria-prima, equipamentos, infraestrutura e recursos humanos. A capacidade está relacionada à habilidade da subsidiária em otimizar a utilização dos recursos.
} 
Para que os recursos não locais possam efetivamente contribuir para a vantagem competitiva da corporação, eles devem atender a três critérios: (i) o valor desses recursos especializados deve ser superior aos disponíveis em outras unidades da corporação; (ii) a matriz deve reconhecer formalmente o valor superior desses recursos; e, (iii) os recursos devem ser passíveis de transferência entre as diferentes subsidiárias.

Birkinshaw, Hood e Jonsson (1998) afirmam que o desenvolvimento de recursos especializados decorre, sobretudo, da visão e das ações da liderança da subsidiária como, por exemplo, buscar novas oportunidades em mercados internacionais em que os recursos especializados possam ser utilizados. Depende ainda da atividade empreendedora da liderança local, ou seja, da disposição proativa da subsidiária. (BIRKINSHAW, 1996).

Quando a iniciativa leva a subsidiária a assumir responsabilidades internacionais, a sua visibilidade dentro da rede corporativa cresce. Mais visibilidade, por sua vez, resulta em mais reconhecimento de sua importância estratégica, o que estimularia o desenvolvimento de novas iniciativas. Sendo assim, Birkinshaw, Hood e Jonsson (1998) afirmam que a iniciativa é o fator mais crítico em fases iniciais da trajetória da subsidiária exatamente porque significa o incremento de sua visibilidade, o que pode levar a uma mudança e evolução do seu papel.

Krishnan (2006), que investigou o empreendedorismo em subsidiárias do setor de software na Índia, observou que, nos estágios embrionários de sua evolução, quando ainda lhes faltava credibilidade, a iniciativa das subsidiárias foi um fator crítico para a conquista de novos negócios. A análise de três multinacionais indianas do setor de software revelou que a evolução do papel das subsidiárias ocorreu em um ambiente em que havia um baixo grau de integração com a matriz e alto nível de autonomia. Assim, os resultados desta pesquisa diferem daqueles encontrados em pesquisas anteriores (Birkinshaw; Hood; Jonsson, 1998) que associavam integração e autonomia com o desenvolvimento da subsidiária.

Birkinshaw e Hood (1998) afirmam que as três perspectivas interagem determinando, de maneira contínua, o papel assim como a evolução da subsidiária. Em outras palavras, para os autores a redefinição do papel da subsidiária deve ser vista a partir da inter-relação entre as três perspectivas - determinismo ambiental, determinação da matriz e escolha da subsidiária. Segundo eles, a subsidiária é uma entidade semi-autônoma e capaz de tomar suas próprias decisões, mas suas ações são limitadas pelas demandas da matriz e pelas oportunidades existentes no ambiente local. A evolução da subsidiária é, então, o resultado da acumulação (ou perda) de capacidades no tempo e do estabelecimento ou perda de missão (charter) ${ }^{8}$.

\footnotetext{
${ }^{8}$ Birkinshaw e Hood (1998) definem missão (charter) como a delegação pela matriz da responsabilidade por determinadas atividades a uma subsidiária. O charter é definido tanto em termos de mercado quanto em termos de produtos manufaturados, de tecnologias utilizadas, de áreas funcionais cobertas ou de qualquer combinação desses fatores.
} 
Outsourcing de TI e redefinição do papel da subsidiária: um estudo comparativo entre as subsidiárias brasileira e indiana de uma multinacional americana

\section{METODOLOGIA}

Com o objetivo de analisar como o offshoring de TI contribui para definir o papel da subsidiária no contexto da corporação foi utilizado o método do estudo comparativo de casos (Yin, 2001), de natureza qualitativa. O método do estudo de caso consiste no exame intensivo de um ou mais objetos de estudo com o propósito de se ter um entendimento profundo e completo desse objeto (Greenwood, 1973; Yin, 2001; Eisenhardt, 1989; SOY, 1997; Goode; Hatt, 1973) empregando-se, para isso, diferentes técnicas de coleta de dados.

A pesquisa de natureza qualitativa permite explorar em profundidade o impacto das variáveis estudadas sendo especialmente recomendada para pesquisas com foco no comportamento humano. (Bonoma, 1985). Por permitir o contato direto com o fenômeno estudado por meio das pessoas nele envolvidas, essa aproximação permite ao pesquisador entender não somente o que é óbvio, mas também o que está latente (Milles; Huberman, 1994), além de uma visão holística do contexto. (Godoy, 1995). Por se tratar de um assunto cuja agenda de pesquisa ainda é recente, o método do estudo de caso é a estratégia mais apropriada para descobrir e explorar novas áreas, assim como desenvolver hipóteses. (Milles; Huberman, 1994).

Ressalte-se que, em estudos dessa natureza, a escolha dos objetos empíricos se baseia não na perspectiva de incidência de fenômenos, mas no interesse do caso em relação ao fenômeno em estudo e nas variáveis potencialmente relevantes. Os casos devem ser selecionados quando se espera encontrar (i) resultados semelhantes nas diversas unidades investigadas ou (ii) resultados diferentes em razão de fatores previamente antecipados pelo pesquisador. Assim, os estudos de casos não são realizados com fins de generalização estatística, mas de compreensão em profundidade de um fenômeno específico, possibilitando uma descrição indutiva e rica (Easton apud Halinen; Törnroos, 2005).

A fim de alcançar os objetivos da pesquisa, selecionaram-se subsidiárias de uma corporação americana em dois países - Brasil e Índia — que exercem atividades de offshoring. A escolha da corporação analisada bem como das suas subsidiárias teve como critério o fato de tratar-se de uma das maiores do setor de TI no mundo. Com a seleção de casos em que o fenômeno se apresenta de forma intensa - representatividade mundial da corporação em relação a serviços de TI e subsidiárias localizadas em países que se destacam na área de TI -, as evidências oriundas de estudos de casos múltiplos tendem a ser mais convincentes. Ademais, é relevante ressaltar as diferenças entre os ambientes (Brasil e Índia) em que se localizam as subsidiárias (casos), de modo a se poder comparar aspectos relacionados à determinação da matriz e à determinação da subsidiária.

As fontes principais de evidências em um estudo de casos de natureza qualitativa são as entrevistas, os documentos e arquivos e a observação (Yin, 2001; Eisenhardt, 1989; Soy, 1997). Neste estudo, privilegiaram-se as entrevistas em profundidade e os dados secundários provenientes de documentos e arquivos. A entrevista é uma das técnicas mais importantes em estudos qualitativos. Seu objetivo é estabelecer ou descobrir as perspectivas ou pontos de vista sobre fatos, tendo como objetivo a 
compreensão detalhada das crenças, atitudes, valores e motivações, em relação aos comportamentos das pessoas em contextos sociais específicos. (Farr, 1982; Gaskell, 2003). Já a análise de documentos constitui-se em uma alternativa de coleta importante em relatórios gerenciais, website das empresas, relatórios governamentais, entre outros. O uso de várias técnicas de coleta de dados em estudo de casos também permite chegarse a evidências mais robustas, o que é conhecido como triangulação (JICK, 1979), provendo maior qualidade em estudos de casos.

A primeira etapa da coleta consistiu em um levantamento documental com base em documentos de associações de classe, tais como a Sociedade Brasileira para a Promoção da Exportação de Software (SOFTEX) e a Brazilian Association of Information Technology and Communication Companies (BRASSCOM). Além disso, foram coletados dados e estatísticas governamentais relacionados à indústria de TI, entrevistas concedidas pelos executivos das subsidiárias estudadas a revistas nacionais e internacionais, dados de empresas de consultoria que realizam levantamentos estatísticos sobre o setor de TI, bem como dados relativos à história e à estratégia, perfil e atuação da corporação e das respectivas subsidiárias analisadas.

Em seguida, realizaram-se entrevistas em profundidade cujo roteiro baseou-se no conjunto de variáveis identificadas a partir do referencial teórico - competências da subsidiária em $\mathrm{P} \& \mathrm{D}$, produção, vendas, marketing e gerência internacional e fatores determinantes do desenvolvimento da subsidiária - escolha da subsidiária (orientação empreendedora e iniciativa); determinismo ambiental (ambiente global e ambiente local); e determinação da matriz (comunicação e integração, autonomia, credibilidade, centralização do processo decisório e delegação de responsabilidades internacionais).

A seleção dos respondentes em cada um dos casos estudados obedeceu aos seguintes critérios: (i) influência na definição das ações e das estratégias offshore da subsidiária e (ii) nível do cargo ocupado pelos executivos. As entrevistas duraram em média duas horas cada uma e foram realizadas durante o terceiro trimestre de 2007. Foram realizadas nove entrevistas com executivos alocados em diferentes serviços de terceirização - Desenvolvimento e Manutenção de Aplicações (AS); Gerência de Infraestrutura (ITD); e Processos de Negócios (BPO) nas subsidiárias brasileira e indiana. Na matriz América Latina, foram realizadas três entrevistas (Executivo AS América Latina; Diretor Offshore América Latina e Vice-Presidente América Latina ITD); na subsidiária brasileira foram realizadas mais três entrevistas (Gerente Offshore ITD; Gerente Offshore AS e Gerente BPO); e, finalmente, na subsidiária indiana, foram entrevistados três executivos (Vice-Presidente Offshore ITD; Vice-Presidente Offshore AS e Vice-Presidente Offshore BPO. 


\section{DESCRIÇÃO DOS CASOS}

\section{1 - Histórico do caso Gama ${ }^{9}$}

A MNE estudada foi fundada nos EUA, no final do século XIX. Em decorrência de seu crescimento rápido e contínuo, a empresa criou, no final da década de 1940, uma subsidiária inteiramente independente cujo objetivo era aumentar as vendas, os serviços e a produção fora dos Estados Unidos. As atividades resultantes da formação dessa unidade, que não existe mais, estendem-se atualmente por mais de 150 países. Há fábricas e laboratórios na França, Alemanha, Espanha, Itália, Holanda, Suécia, Inglaterra, Brasil, Argentina, Colômbia, México, Canadá, Austrália e Japão. Os 29 laboratórios de desenvolvimento atuam juntamente com os cinco centros de pesquisa pura, onde são realizadas pesquisas tecnológicas de ponta.

Um acontecimento-chave na trajetória de Gama foi determinante para a sua evolução. A empresa foi um dos principais fornecedores das forças armadas americanas durante a Segunda Guerra Mundial. O contrato com as Forças Armadas garantiu os recursos necessários para o desenvolvimento da empresa, além de permitir o acesso à tecnologia desenvolvida nas universidades americanas. Assim, mais valioso do que os lucros auferidos pelos contratos, foi o acesso à tecnologia de computadores digitais desenvolvida sob a coordenação dos militares, o que permitiu à empresa, após a guerra, lançar no mercado equipamentos com tecnologia extremamente sofisticada.

Na década de 1960, a empresa fez um investimento significativo na criação de uma arquitetura-padrão que permitia a portabilidade de software entre computadores (hardwares) de diferentes capacidades. Essa criação acabou por consolidar sua posição no mercado como uma das maiores empresas de TI do mundo.

Com o amadurecimento da indústria de serviços de TI e o surgimento de novos competidores globais, especialmente empresas indianas, a corporação deu um novo passo em sua estratégia para se consolidar como uma empresa global: adotou um modelo de organização globalmente integrada. Esse modelo tem duas características essenciais. Com relação à primeira, até muito recentemente, as corporações produziam bens e serviços no mesmo lugar em que os vendiam. Atualmente, as organizações investem, sobretudo, em locais que podem suprir o mercado global, reduzindo assim, os custos de produção. A segunda característica diz respeito à padronização de tecnologia, o que permite às corporações terceirizar serviços para outras empresas ou para subsidiárias localizadas em outros países.

\footnotetext{
${ }^{9}$ Gama é um nome fictício.
} 


\section{2 - A subsidiária indiana}

A Índia é provavelmente o melhor exemplo da revolução ocorrida na área de TI, especialmente no que concerne ao offshoring de TI. As empresas indianas vêm apresentando taxas excepcionais de crescimento na exportação de softwares desde a década de 1990. O setor de TI da Índia responde por cerca de 70\% do mercado global de offshoring de TI. (Corbett, 2004; Arora; Gambardella, 2005).

\subsection{1 - Características gerais da subsidiária indiana}

A multinacional Gama opera na Índia desde o início da década de 1990, quando o mercado indiano reabriu para empresas estrangeiras. Gama estabeleceu uma joint venture com uma empresa local e cresceu modestamente até o ano 2000, momento em que a joint venture se desfez e Gama assumiu o controle total da subsidiária. Em 2004, Gama adquiriu uma empresa de serviços de terceirização de processos de negócio (BPO). Em 2006, já era uma das cinco maiores empregadoras do setor de TI da Índia, com mais de 40 mil empregados. Somente as empresas domésticas - Wipro, TCS, Infosys - empregavam mais pessoas.

Desde a entrada de Gama na Índia, a empresa teve como prioridade estabelecer as melhores práticas de gestão na subsidiária tendo sido certificada com o ISO $9001 \mathrm{em}$ meados da década de 1990 e com o $\mathrm{CMM}^{10}$ (nível cinco) no final dessa mesma década. Nessa mesma época, Gama estabeleceu seu primeiro laboratório de pesquisa na área de software e, em 2005, o primeiro laboratório de pesquisa de serviços.

Embora responda por menos de um por cento do faturamento de Gama, atualmente, a subsidiária indiana é a maior em número de empregados. Em termos de faturamento, é a unidade da corporação que mais tem crescido percentualmente. Em 2006, por exemplo, o faturamento da subsidiária cresceu mais de $30 \%$, sendo que, no segundo quartil desse ano, o crescimento foi da ordem de $60 \%$. Por causa disso, e também em virtude da escolha da Índia como plataforma de operações offshore, é uma subsidiária que tem recebido atenção especial da corporação, seja no monitoramento do crescimento dos competidores locais, e as parcerias com governo e universidades para o aproveitamento das competências criadas são exemplos do interesse dispensado pela corporação à subsidiária indiana.

\footnotetext{
${ }^{10}$ CMM - Capability Maturity Model, também conhecido como Software CMM (SW-CMM), refere-se ao conjunto das melhores práticas para o diagnóstico e a avaliação da maturidade do desenvolvimento de softwares em uma organização. O CMM fornece às organizações orientação sobre como controlar o processo de desenvolvimento de software e como evoluir para uma cultura de excelência na gestão de softwares.
} 
Outsourcing de TI e redefinição do papel da subsidiária: um estudo comparativo entre as subsidiárias brasileira e indiana de uma multinacional americana

\subsection{2 - Atividades realizadas}

Embora, num primeiro momento se enquadrasse dentro do objetivo de redução de custo por meio da utilização de mão-de-obra mais barata, gradualmente a subsidiária indiana ganhou mais relevância, deixando de ser simplesmente uma fornecedora desse tipo de recurso. Atualmente, executa atividades de pesquisa, tem laboratórios de desenvolvimento e centros de excelência que prestam serviços para toda a corporação, oferece serviços de consultoria e é responsável por uma parte expressiva das exportações de serviços.

No segmento de serviços de TI, a subsidiária tem sob sua responsabilidade: (i) o laboratório de desenvolvimento de software; (ii) o laboratório de pesquisa em soluções e-business e de serviços; (iii) os centros de excelência em Linux e soluções de negócios; (iv) o desenvolvimento e a manutenção de aplicações - Aplication Services (AS); (v) a terceirização de processos de negócio - Business Process Outsourcing (BPO); e (vi) a terceirização de serviços de infraestrutura de TI - Infrastructure Technology Delivery (ITD).

Criado em 2005, o laboratório de P\&D em serviços é o primeiro da corporação nessa área. Esse laboratório permitiu à subsidiária assumir a responsabilidade pelo desenvolvimento de novos padrões a serem utilizados por todas as outras unidades da corporação. A subsidiária tem ainda a responsabilidade pela aplicação de tecnologias inovadoras visando melhorar os serviços de TI; pelas melhorias das metodologias aplicadas; e pela entrega desses serviços em escala global. Esse laboratório de P\&D tem ampliado o papel contribuidor da subsidiária, aumentando, assim, sua participação internacional em uma área considerada crítica para o futuro da corporação.

Além de sua importância para a inovação, a subsidiária indiana exporta serviços - AS, BPO e ITD - desde o ano 2000. A maior parte - cerca de $80 \%$ - dos recursos humanos da subsidiária dedica-se à exportação - principalmente intrafirma - de serviços tais como desenvolvimento e manutenção de aplicações, terceirização de processos de negócio e gestão da infraestrutura de TI. Há ainda os clientes externos mais de 200 - atendidos por meio de offshoring.

\subsection{3 - Escolha da subsidiária}

Um assunto recorrente no dia-a-dia da subsidiária é a necessidade de iniciativa e inovação. Um exemplo disso foi a atuação do gerente-geral para convencer a corporação acerca da necessidade da incorporação de $100 \%$ da subsidiária no final da década de 1990. Graças a essa iniciativa, criou-se a base que permitiu o crescimento substancial da subsidiária nos últimos anos. A importância conferida aos laboratórios de $P \& D$, que têm a função de desenvolver soluções inovadoras, demonstra, por sua vez, como a inovação é um traço distintivo dessa subsidiária.

Existe um apoio explícito da alta direção de Gama às decisões de risco tomadas na subsidiária indiana. A capacidade dessa subsidiária em aumentar sua produtividade e 
em reduzir seus custos - 10\% ao ano, em média - por iniciativa própria, em detrimento das pressões decorrentes do aumento de custos (salários e benefícios, por exemplo) nos últimos anos, é resultado principalmente da aplicação de metodologias inovadoras desenvolvidas na subsidiária.

Um efeito direto das iniciativas da subsidiária indiana é o investimento maciço da corporação no amadurecimento e no uso das capacidades criadas por essa subsidiária e na aquisição de empresas locais, o que lhe permite acessar novos conhecimentos. A matriz tem investido ainda em parcerias com universidades. Essas parcerias entre a subsidiária e as universidades indianas se iniciaram após a criação, conjuntamente com o Indian Institute of Information Techonology (IIIT), de um laboratório de pesquisa. Entre 2004 e 2005, foram firmadas parcerias com 300 institutos de educação com o propósito de treinar 75 mil estudantes de diferentes níveis. No ano de 2006, essa parceria estendeu-se a outros 745 institutos de educação. Tais parcerias têm essencialmente o objetivo de capacitar estudantes, agentes governamentais, fornecedores e clientes, ajudando-os a inovar.

Os executivos da subsidiária trabalham ainda junto ao governo, oferecendo-lhe subsídios para tomar decisões que visem incentivar a indústria de TI; defendendo a necessidade de investimentos nas áreas de educação e infraestrutura tecnológica; e, por fim, ressaltando a importância de se ter regras claras a fim de tornar a Índia uma referência mundial no setor de TI. Além de sua atuação junto ao governo, a subsidiária integra a National Association of Software and Services Companies (NASSCOM), organização da qual Gama é também membro do conselho executivo.

\subsection{4 - Determinação da matriz}

A corporação elegeu a Índia um dos emerging business oportunities. Foi a primeira vez que um país, em vez de uma tecnologia, produto ou serviço, foi escolhido como uma oportunidade de negócio, ou seja, apto a receber mais recursos. Além disso, a subsidiária indiana passou a ter acesso direto à corporação, e não mais mediante o headquarter regional.

O número expressivo de laboratórios de P\&D estabelecidos na Índia, em parceria com entidades locais, é outro exemplo de determinação estratégica da matriz. Em 1998, a subsidiária estabeleceu um centro de educação, em parceria com o Indian Institute of Information Technology (IIIT), para oferecer aos estudantes da instituição cursos de curta duração. No mesmo ano, foi montado em New Delhi, ao lado do campus da IIIT, o primeiro laboratório de pesquisa de Gama na Índia.

Outro fator que tem contribuído para a ampliação contínua da responsabilidade internacional da subsidiária é a designação de executivos de origem indiana para ocupar diversos cargos-chave na matriz, o que facilita a comunicação e o relacionamento entre a matriz e a subsidiária.

Como resultado dessas ações da matriz, a responsabilidade internacional da subsidiária indiana vem aumentando de forma considerável. A importância do laboratório de serviços, que a matriz utiliza como referência para definir padrões para 
Outsourcing de TI e redefinição do papel da subsidiária: um estudo comparativo entre as subsidiárias brasileira e indiana de uma multinacional americana

outras unidades, e o estabelecimento de centros de excelência na área de software nesse país ilustram a mudança na relevância dessa subsidiária no contexto da corporação.

Segundo os entrevistados, o fator determinante para a subsidiária indiana ter conquistado atividades de offshoring foi o Bug do Milênio, em 1999, quando todas as aplicações envolvendo o manuseio de datas precisaram ser revistas. Como a quantidade de trabalho necessária era imensa, as empresas necessitavam de fornecedores com competência para realizar esse trabalho, além de abundância de mão-de-obra barata. A Índia foi capaz de absorver esse trabalho e, assim, tornar-se uma referência no fornecimento de serviços de TI. Ademais, a capacidade das empresas indianas em compreender a demanda do mercado, que se baseava na contratação de serviços ou mão-de-obra de TI, e não na compra de produtos ou pacotes completos de TI, contribuiu para redefinir o lugar da Índia no setor de TI. A qualidade na prestação de serviços, além do tipo de serviço oferecido, acabou por ser associada à Índia como um todo, e não apenas a fornecedores específicos. O país adquiriu, então, uma excelente reputação como fornecedor de serviços offshore.

\subsection{5 - Determinismo ambiental}

Em função do crescimento econômico robusto, a Índia tem recebido um volume expressivo de investimentos estrangeiros diretos (IDE). O crescimento econômico consistente e os fluxos de IDE têm, por sua vez, contribuído para acelerar os investimentos públicos - infraestrutura - e privados - desenvolvimento de novas tecnologias. Em razão dessas transformações, a composição do PIB indiano tem se modificado, concentrando-se, cada vez mais, em serviços e manufatura, reduzindo-se, assim, a importância do setor primário.

Além da consolidação do processo de reformas, a Índia tem uma notável infraestrutura de educação técnica e superior. São 250 universidades, 1,5 mil institutos de educação e mais de 10 mil centros de educação superior que, juntos, formam mais de 14 mil PhDs, 200 mil engenheiros e 300 mil não engenheiros pós-graduados e aproximadamente 2 milhões de graduados por ano. Acrescente-se a isso o fato de a Índia ter uma mão-de-obra de baixo custo que, adicionalmente, tem a vantagem de dominar o idioma inglês.

Em função da estabilidade política e econômica e do volume de mão-de-obra qualificada, barata e com domínio da língua inglesa, a Índia tem atraído volumes crescentes de investimentos estrangeiros. Várias empresas globais instalaram laboratórios de P\&D no país, sendo que, em muitos casos, esses laboratórios são maiores do que os existentes no país da matriz. Todos esses fatores têm em conjunto contribuído para assegurar não apenas a inserção, mas um papel significativo da Î́ndia no setor de TI.

No que tange à relação entre governo e empresas, as associações do setor constituem o principal canal de diálogo entre as duas partes. A NASSCOM, por exemplo, tem tido um papel fundamental no sentido de ajudar a minimizar as ineficiências ainda existentes na estrutura de governo. A subsidiária indiana mantém 
ainda parceria com 15 governos estaduais apoiando projetos de $e$-business.

Outro aspecto importante da relação entre as duas partes são os incentivos fiscais concedidos pelo governo às empresas de TI. As unidades de exportação de serviços da subsidiária indiana estão todas localizadas em parques tecnológicos, que têm isenção de imposto de renda até 2009 e isenção de impostos de importação para hardware e software.

Em suma, há um consenso de que o país somente manterá as atuais taxas de crescimento se for capaz de inovar. Dois componentes são vistos como fundamentais para que isso seja possível: (i) a existência e a capacitação de recursos adequados e (ii) a atuação de empresas locais indianas, que são agora grandes empresas globais, criando uma concorrência que atrai investimentos e a atenção de MNEs.

\section{3 - A subsidiária brasileira}

Ao se pensar em exportação de serviços de TI, o Brasil situa-se em um segundo nível, atrás de países como a Índia, por exemplo. Segundo Carmel e Tjia (2005), a posição brasileira deve-se a diferentes razões, entre as quais à condição econômica ainda instável, ou seja, à volatilidade de seus indicadores econômicos. No entanto, os autores enfatizam que o Brasil pode se sobressair por contar com mão-de-obra qualificada de custo relativamente baixo, se comparada à mão-de-obra de outros países que competem por oportunidades nessa área. De acordo com Sahay, Nicholson e Krishna (2003), o Brasil pode ser competitivo na área de nearsourcing ${ }^{11}$. A proximidade geográfica e a afinidade cultural com alguns dos principais mercados consumidores de serviços de TI favoreceriam o país na disputa por tais mercados.

\subsection{1 - Características gerais da subsidiária brasileira}

A subsidiária brasileira de Gama surgiu no final da década de 1910, a partir de um investimento do tipo greenfield. Sendo a maior e mais antiga empresa de serviços de TI do Brasil, foi uma catalisadora importante no crescimento do setor de TI do país.

Durante muitos anos, a subsidiária supria apenas o mercado local, mas, recentemente, por ter mão-de-obra qualificada e relativamente barata disponível no país, a subsidiária foi escolhida para exportar serviços em diferentes segmentos. Desde o momento em que iniciou o processo de exportação, o segmento de serviços de TI tem crescido continuamente. Em 2006, por exemplo, esse segmento cresceu cerca de $10 \%$ em termos de faturamento. Por causa desses resultados, a subsidiária brasileira tem recebido investimentos da corporação com o objetivo de aumentar a sua capacidade

\footnotetext{
${ }^{11} \mathrm{O}$ termo nearsourcing refere-se ao fornecimento de serviços a clientes localizados em um país geográfica e/ou culturalmente próximo. O nearsourcing tem algumas vantagens: (i) proximidade geográfica, ou seja, menor diferença em termos de fuso horário; (ii) compatibilidade cultural; e (iii) redução de custos.
} 
Outsourcing de TI e redefinição do papel da subsidiária: um estudo comparativo entre as subsidiárias brasileira e indiana de uma multinacional americana

produtiva.

Como Gama, a corporação acredita que a subsidiária brasileira tem o potencial de se tornar um centro offshore de serviços. Em 2001, a corporação fez um importante investimento na implementação de um centro de dados na região de Campinas (SP), a partir do qual a subsidiária brasileira entrega serviços de gerenciamento de infraestrutura $^{12}$ para o Brasil e também para os EUA.

Desde a criação da unidade de serviços em 1992, tem havido mais ênfase da subsidiária na adoção das melhores práticas de gestão de TI. A subsidiária foi certificada com o ISO 9001, em meados da década de 1990, e com o CMMI (5), em meados da década de 2000. Apesar de ainda não contar com laboratórios de pesquisa, a subsidiária brasileira tem centros de tecnologia ${ }^{13}$ que funcionam em parceria com unidades de desenvolvimento localizadas em outros países.

\subsection{2 - Atividades realizadas}

A partir do centro de dados instalado na região de Campinas, que fornece serviços para os EUA e a Europa, a subsidiária executa as seguintes funções no segmento de serviços de TI: (i) desenvolvimento e manutenção de aplicações; (ii) terceirização de processos de negócios; e (iii) terceirização de serviços de infraestrutura de TI.

Há um departamento da subsidiária encarregado de entregar tanto serviços offshore quanto domésticos. No caso do offshore, a exportação de serviços, predominantemente intrafirma, permite a transferência de custos entre unidades. Há ainda cerca de 50 clientes externos atendidos parcialmente ${ }^{14}$ em seus contratos de terceirização por meio do offshoring. Atualmente, cerca de 7000 empregados trabalham na área de serviços, sendo que aproximadamente a metade deles dedica-se às atividades de exportação. A exportação de serviços tem sido, na realidade, o principal responsável pelo aumento do número de empregados na empresa. No ano de 2006, por exemplo, houve um aumento de $80 \%$ do número de empregados alocados na exportação de serviços.

\footnotetext{
12 A infraestrutura de TI - servidores, sistemas operativos, armazenamento e redes - é um ativo estratégico e a base fundamental que permite que o software proporcione os serviços e as aplicações de que uma empresa necessita para operar eficazmente. Para muitas organizações, o rápido crescimento e desenvolvimentos das novas tecnologias traduziram-se em complexas infraestruturas de centros de dados e de computadores pessoais difíceis de gerenciar. A maioria das organizações reconhece a importância de uma infraestrutura de TI otimizada e eficiente em termos de custos.

${ }^{13}$ Centros de tecnologia são extensões de laboratórios de desenvolvimento.

${ }^{14}$ Parcialmente porque o Brasil supre apenas parte dos serviços de outsourcing/offshoring contratados pelos clientes de Gama. Outros serviços são supridos por unidades de outros países - EUA e/ou Índia.
} 


\subsection{3 - Escolha da subsidiária}

Existe uma percepção, por parte da direção da subsidiária brasileira, de que o offshoring é uma oportunidade que pode trazer benefícios no futuro. Sendo assim, diversas iniciativas - elaboração de ações junto ao governo para incentivar a competitividade do setor de TI brasileiro; criação de um departamento dedicado ao planejamento e desenvolvimento de ações para aumentar a competitividade e a visibilidade dessa subsidiária; e, por fim, alocação de recursos para atividades de estruturação do offshoring - têm sido empreendidas com o propósito de viabilizar essa oportunidade.

De modo geral, há um ambiente de iniciativa e proatividade em torno da oportunidade de exportação de serviço, mas não na agressividade considerada necessária pelos entrevistados para se obter os resultados desejados. Além disso, não existe hoje uma conjunção favorável para o offshoring, devido à recente valorização da moeda brasileira e à escassez de recursos humanos ${ }^{15}$. Assim, a subsidiária tem perdido relevância em comparação com outras unidades da corporação, embora, em números absolutos, ainda seja a segunda subsidiária no mundo em número de recursos humanos alocados para a exportação.

Embora seus executivos entendam que o offshoring possa trazer benefícios para a subsidiária brasileira, essa oportunidade ainda não é relacionada ao incremento de sua responsabilidade internacional, mas ao ganho de escala que o offshoring pode representar para os negócios locais, ou seja, o ganho de escala poderia diminuir os custos para os clientes locais. Isso ocorre porque os incentivos financeiros concedidos aos executivos ainda estão associados em grande parte à geração de renda local, e não ao comércio entre as diferentes subsidiárias.

Ainda de acordo com os entrevistados, não há na subsidiária brasileira uma efetiva atmosfera propícia à inovação. Para eles, (i) o foco está na implementação de padrões e controles estabelecidos pela corporação; (ii) há um ambiente de aversão ao risco, que se reflete na preocupação constante em estar preparado para quaisquer auditorias corporativas; e (iii) não há a preocupação de se criar iniciativas para participar de projetos de geração de conhecimento, nem iniciativas para definir, conjuntamente com a matriz, as estratégias. Como não há foco em inovação, a subsidiária tem tido dificuldade de se posicionar de maneiras alternativas perante a corporação. Outro problema apontado pelos entrevistados é a dificuldade relativa à alocação de recursos para os projetos de exportação, o que, na opinião desses entrevistados, se deve a falhas na implementação de um modelo mais eficiente de gestão.

\footnotetext{
${ }^{15}$ Com relação ao custo e à oferta/escassez da mão-de-obra, deve-se observar que: (i) em termos de qualificação, tanto a mão-de-obra brasileira quanto a indiana, são bem qualificadas (excetuando-se a questão do domínio da língua inglesa), mas a Índia tem uma oferta muito maior, o que lhe permite suprir uma grande parte da demanda mundial por esse tipo de mão-de-obra; (ii) mesmo tendo capacidade de suprir esse tipo de mão-de-obra, as empresas multinacionais, por uma questão de risco, buscam mão-deobra barata em outros países; e (iii) a questão do custo da mão-de-obra é relativa. Na Índia, é mais barata que no Brasil; e, neste, mais barata que nos EUA e Europa.
} 
Embora não percebam a priorização das atividades relacionadas ao offshoring, os entrevistados ressaltam existir oportunidades ainda não exploradas pela subsidiária. Um exemplo é a existência de conhecimento técnico no Brasil (ou na subsidiária) na área de grandes computadores, que não é devidamente explorado. O Brasil é o terceiro mercado no mundo em grandes computadores, depois dos EUA e da Alemanha. Se mais bem explorado, esse conhecimento poderia dar origem a um centro de excelência nessa área.

Identificou-se a existência de oportunidades de recursos não-locais ainda não exploradas na agressividade adequada pela subsidiária. Um exemplo é a existência de conhecimento técnico diferenciado no Brasil na área de grandes computadores (mainframe). O Brasil é o terceiro mercado no mundo em grandes computadores, depois dos EUA e da Alemanha. Esse diferencial pode ser explorado para a criação de centros de excelência no Brasil, o que não existe hoje.

\subsection{4 - Determinação da matriz}

A subsidiária brasileira é vista pela corporação no contexto dos países emergentes com índices de crescimento econômico expressivo. No caso da subsidiária brasileira, por causa do baixo custo relativo da mão-de-obra, Gama elegeu-a para fornecer serviços de exportação em todos os segmentos de serviços, principalmente para o mercado dos EUA. Ressalte-se que foi da matriz a iniciativa de designar a responsabilidade offshore à subsidiária, dentro de uma estratégia de redução de custos. Como essa subsidiária demonstrou ter recursos dificilmente encontrados em outros países como, por exemplo, conhecimento técnico na área de grandes computadores (mainframes), isso contribuiu para consolidar o seu papel de exportadora de serviços.

A existência de um estreito vínculo entre a matriz e a subsidiária brasileira reflete a credibilidade conquistada pela subsidiária que, historicamente, tem cumprido as metas e alcançado os resultados esperados - aumento do faturamento e aumento de sua responsabilidade offshore. Embora tenha desenvolvido uma relação de proximidade com a matriz, a autonomia da subsidiária brasileira ainda é limitada. No que se refere aos serviços locais, existe autonomia de relacionamento com os clientes domésticos e também com os fornecedores. No entanto, todos os processos de negócios, entrega de serviços e ferramentas de gestão são definidos por outras unidades da corporação.

\subsection{5 - Determinismo ambiental}

De acordo com os entrevistados, como o governo brasileiro deseja aumentar a competitividade do setor de TI, ele tem oferecido apoio e incentivo às empresas exportadoras de serviços de TI. Há apoio e incentivo para a exportação de serviços de TI e para o aumento da competitividade do setor. Os executivos têm trabalhado junto ao governo para estabelecer parcerias relativas a treinamento e educação, com o objetivo de garantir a oferta de recursos humanos no futuro. 
Embora haja uma preocupação da área governamental acerca da capacidade do setor educacional suprir recursos humanos qualificados - conhecimentos técnico e linguístico - na quantidade exigida pelo mercado, ainda não saíram do papel algumas iniciativas, que tinham como objetivo capacitar recursos humanos. Em decorrência dessa dificuldade, a subsidiária brasileira tem procurado investir em cidades, fora do eixo Rio-São Paulo, em que há oferta de recursos humanos qualificados.

Existe, então, a percepção de que o governo ainda não é ágil o suficiente para efetivar ações fundamentais para o desenvolvimento do setor de TI. Alguns entrevistados consideram a deficiência administrativa de certos órgãos governamentais como um dos principais entraves para que o Brasil se torne um dos principais fornecedores do mercado offshore.

\section{DISCUSSÃO DOS CASOS}

A análise da trajetória da subsidiária indiana evidencia que sua evolução estratégica ocorreu, primeiramente, com a identificação e o desenvolvimento de seus recursos não locais. A subsidiária utilizou, então, suas próprias capacidades para agregar valor a esses recursos de modo a torná-los competências reconhecidas pela corporação. Por fim, essas competências transformaram-se em atividades que refletem a maior responsabilidade internacional da subsidiária. Portanto, no caso dessa subsidiária, a designação da atividade offshore pela matriz foi subsequente ao desenvolvimento de suas capacidades.

O offshoring foi, assim, fundamental para a evolução da subsidiária. Mais importante, o desempenho da subsidiária indiana no que concerne às atividades de offshoring contribuiu para aumentar a sua credibilidade e a sua visibilidade dentro da corporação e levou a matriz a lhe atribuir outras responsabilidades internacionais. Essa atribuição coincidia com o desejo da alta direção da subsidiária em assumir mais responsabilidades, pois o mercado interno indiano ainda é pequeno, e não oferece tantas oportunidades de crescimento. Essas responsabilidades contribuíram para o reposicionamento estratégico da subsidiária indiana dentro da corporação. Ao receber mais responsabilidades internacionais - o laboratório de pesquisa em serviços, por exemplo - a subsidiária indiana evolui da posição de contribuidora especializada para a posição de mandato mundial, em que efetivamente a subsidiária contribui para a geração de conhecimento da corporação (Gupta; Govindarajan, 1991; White; Pointer, 1984).

Outros fatores críticos para a evolução estratégica da subsidiaria indiana foram: sua orientação empreendedora (Birkinshaw, 1996), sobretudo no que se refere ao posicionamento da direção em relação a riscos e ao estabelecimento de objetivos agressivos de redução de custo e de comércio intrafirma; indicação de pessoas de origem indiana para postos-chave da matriz; e adoção de uma estratégia baseada na inovação. Conjuntamente, esses fatores contribuíram para que a subsidiária assumisse novas responsabilidades internacionais, principalmente em atividades de pesquisa em serviço. A criação do laboratório de $\mathrm{P} \& \mathrm{D}$ em serviços, por exemplo, exemplifica uma vantagem não local (Birkinshaw; Hood; Jonsson, 1998; Rugman; Verbeke, 2001) que 
Outsourcing de TI e redefinição do papel da subsidiária: um estudo comparativo entre as subsidiárias brasileira e indiana de uma multinacional americana

ilustra como a iniciativa da subsidiária indiana foi determinante de sua evolução.

Outro fator determinante foi a transformação no ambiente global (Carmel; Tija, 2005; Birkinshaw; Hood; Jonsson, 1998) e, em particular, a globalização do setor de TI, o que gerou a necessidade de racionalização mediante economias de escala e redução de custo e, em consequência, a alocação de atividades para subsidiárias com custo menor. Isso levou a matriz a mudar seu modelo organizacional, adotando o modelo global integrado e designando uma série de responsabilidades para outras subsidiárias. Nesse contexto, em função de seus recursos e capacidades, novas responsabilidades foram atribuídas à subsidiária indiana.

Do ponto de vista do ambiente local (Porter, 1990), o surgimento de grandes empresas indianas competindo no mercado global forçou as MNEs de outros países a se estabelecer no País e, em consequência, a fazer uso das vantagens dos recursos não locais dessas empresas. O governo local, por sua vez, tem buscado criar um ambiente favorável à exportação de serviços por meio da criação de instituições e regras estáveis ao longo do tempo e de incentivos à indústria de TI, da diminuição de taxas e do desenvolvimento de parques tecnológicos com a presença de grandes corporações.

A análise da trajetória da subsidiária brasileira, por sua vez, mostrou que a atividade de offshoring, determinação da matriz, foi anterior ao surgimento da capacidade na subsidiária. O offshoring aumentou a credibilidade e a visibilidade da subsidiária brasileira dentro da corporação, facilitando a expansão de suas atividades internacionais, como exportação de serviços de TI, mas não resultou, todavia, na diversificação de suas responsabilidades. Sendo assim, inicialmente, a evolução deveuse a uma determinação da própria matriz, mas, posteriormente, ao baixo custo da mãode-obra local.

A expansão das responsabilidades internacionais da subsidiária brasileira, dentro de um mesmo charter, evidencia o seu papel de contribuidor especializado (White; Pointer, 1984). Mais recentemente, contudo, em função do aumento do custo, em dólar, tornando o ambiente local menos atrativo, do seu estilo de gestão e da falta de iniciativas inovadoras no sentido de explorar novos recursos ou capacidades, a subsidiária brasileira pode perder a condição de fornecedora offshore de determinados serviços. Assim, em um contexto em que a subsidiária perde competitividade em termos de custo e suas iniciativas mostram-se insuficientes para consolidar sua posição de exportadora de serviços, sua relevância estratégica no âmbito da organização poderá se alterar no futuro.

Ao se comparar as trajetórias das subsidiárias indiana e brasileira, observa-se que a matriz atribuiu às duas subsidiárias a função offshore, mas há uma distinção importante nos dois casos. Enquanto, no caso da Índia, a função foi atribuída como consequência de iniciativas anteriores da subsidiária, no caso da subsidiária brasileira, a atribuição ocorreu antes do desenvolvimento dessas competências pela subsidiária. Do ponto de vista da relevância estratégica de cada uma delas, ambas evoluíram de forma distinta: enquanto a subsidiária indiana evoluiu para um mandato mundial, a brasileira se consolidou como uma contribuidora especializada.

As particularidades da trajetória dessas duas subsidiárias podem ser analisadas levando-se em conta diferentes fatores. Relativamente à atribuição do papel offshore às 
subsidiárias indiana e brasileira, no caso da primeira, tal atribuição deveu-se, sobretudo, ao fator determinismo ambiental. A existência de grandes empresas indianas competindo no mercado global, os incentivos governamentais e a abundância de recursos humanos levaram a matriz a atribuir a função offshore a essa subsidiária. No caso da subsidiária brasileira, por sua vez, o fator determinante da atribuição foi a existência de um mercado local expressivo e de mão-de-obra de baixo custo, que poderia absorver essas novas funções. O Brasil tinha o recurso não local, mas não tinha ainda a capacidade, ou seja, a competência formada.

A atribuição do papel offshore teve efeitos distintos para a evolução das duas subsidiárias. Para a subsidiária indiana, o offshoring foi fundamental para a subsidiária assumir um papel mais relevante. Por exemplo, os laboratórios de pesquisa instalados nessa subsidiária resultaram em uma participação mais expressiva na geração de conhecimento no âmbito da corporação. De maneira similar, a atribuição do papel offshore foi fundamental para a evolução da subsidiária brasileira, mas, diferentemente da subsidiária indiana, a inexistência de iniciativas próprias, tais como um centro de competência em computadores de grande porte ou de iniciativas para se inserir em atividades de pesquisa da corporação, pode vir a prejudicar sua evolução no sentido de adquirir mais relevância face às outras subsidiárias.

Observe-se ainda que, tanto no caso da subsidiária indiana quanto da brasileira, o fator custo da mão-de-obra foi essencial para a atribuição da atividade offshore. Entretanto, em ambos os casos, esse fator tem gradativamente perdido importância, em virtude de razões discutidas anteriormente, ou seja, a perda de competitividade em termos de custo afeta as duas subsidiárias indistintamente. A evolução do papel da subsidiária depende, assim, de outros fatores. A subsidiária indiana busca aumentar sua relevância estratégica por meio da geração de conhecimento ou da inovação. No caso da subsidiária brasileira, ausência de iniciativas desse tipo pode ter como consequência a perda de responsabilidades internacionais. Sendo assim, a competição interna entre as duas subsidiárias por mais relevância estratégica pode ser um fator explicativo adicional para se compreender a trajetória ou a evolução do papel das subsidiárias.

Da perspectiva da escolha da subsidiária, a trajetória de uma subsidiária é determinada principalmente por suas escolhas relativamente ao uso de seus recursos e de suas capacidades, pelas aspirações de seus executivos e pelas iniciativas dos empregados, ou seja, o caráter empreendedor e a capacidade de iniciativa e de inovação da subsidiária (Birkinshaw, 1996). Na subsidiária indiana, a inovação e a proatividade, configurando o caráter empreendedor da liderança dessa subsidiária, evidenciam a iniciativa dessa subsidiária.

Em contraste, no caso da subsidiária brasileira, as iniciativas resumem-se à busca de parcerias com o governo e sinergia com mercado local, ou seja, suas ações ainda são mais voltadas para atender às demandas do mercado local do que o externo. Nem a inovação, nem o objetivo de evoluir para além do seu papel atual, constituem neste momento prioridades para a liderança da subsidiária brasileira. Para essa liderança, evolução para além do papel de contribuidora especializada ainda está associada ao aumento de market-share e ao faturamento no mercado local. Não há uma associação entre o incremento do papel contribuidor e o aumento de responsabilidades internacionais. 
Outsourcing de TI e redefinição do papel da subsidiária: um estudo comparativo entre as subsidiárias brasileira e indiana de uma multinacional americana

Em termos de políticas públicas, os governos da Índia e do Brasil têm adotado estratégias semelhantes de incentivo à exportação de serviços de TI, mas os resultados obtidos nos dois países são distintos. No caso da Índia, as políticas governamentais aparentam ter sido mais bem-sucedidas. A Índia investiu em um modelo de treinamento de mão-de-obra altamente qualificada que encontrou efetiva demanda no mercado global. O Brasil, por sua vez, investiu em um modelo de desenvolvimento de soluções de TI, que não encontrou a mesma receptividade no mercado mundial. O mercado de offshoring estava mais propício a contratar mão-de-obra (ex: contratar 10 profissionais com conhecimento de Microsoft Windows) do que comprar soluções prontas (ex: um pacote/sistema de TI para controle de faturamento de uma empresa).

Outro fator que contribuiu para modificar a posição desses países no setor de TI foi a competitividade de suas empresas domésticas. Essas empresas contribuíram para propagar a imagem da Índia como principal fornecedora de serviços offshore de TI no mundo. O surgimento de grandes empresas indianas capazes de oferecer serviços em escala global tem, assim, atraído multinacionais de outros países para o País. Instalandose na Índia, as multinacionais não indianas mantêm-se competitivas, pois têm acesso aos mesmos recursos disponíveis às empresas indianas. No caso do Brasil, como a maior parte das empresas é de pequeno e médio porte, não havendo, ainda, nenhuma multinacional brasileira nesse setor, a atratividade do país para as empresas estrangeiras é menor.

\section{CONSIDERAÇÕES FINAIS}

A globalização do setor de TI abriu oportunidades para as duas subsidiárias analisadas. Como descrevem D’Cruz (1986), White e Pointer (1984), Birkinshaw e Morrison (1995), a análise comparativa dos dois casos mostrou que, em resposta à quebra de barreiras internacionais, as subsidiárias se especializam. A subsidiária brasileira recebeu mais responsabilidades, e isso implica o aumento da exportação de serviços, mas a matriz ainda mantém a responsabilidade e o controle como um todo. No caso da subsidiária indiana, o mandato global tornou-se uma oportunidade de participar da geração de conhecimento da corporação.

A análise dos casos mostra também como a exportação de serviços de outsourcing de TI (offshoring) tem alterado a relevância estratégica e redefinido o papel das subsidiárias. Entretanto, o aumento da relevância estratégica depende, sobretudo, da capacidade da subsidiária em desenvolver competências que podem ser transferidas ou utilizadas por outras unidades corporativas. Esse desenvolvimento e, consequentemente, a própria subsidiária pode, então, transformar-se em uma fonte de vantagem competitiva corporativa. Analisando do ponto de vista da relevância estratégica, a posição ocupada pela subsidiária brasileira - contribuidora especializada - é desconfortável, pois baseiase, principalmente, no baixo custo de sua mão-de-obra. Portanto, está à mercê da concorrência de novos entrantes (países em desenvolvimento) e de variações macroeconômicas. Assim, existe o risco de ver sua relevância diminuída no futuro. Sua relevância estratégica não deve se alterar, caso a subsidiária brasileira não reavalie a questão da inovação. 
Conforme Krishan (2006), o fator iniciativa foi crucial para aumentar o papel contribuidor da subsidiária indiana em seus momentos iniciais. Por outro lado, a falta de iniciativa, associada a problemas relativos à capacidade de gestão, tem impedido a subsidiária brasileira de alcançar um papel contribuidor mais relevante. Enquanto a subsidiária indiana agiu proativamente, explorando outras competências locais, mesmo estando em uma posição confortável como maior provedor offshore, a subsidiária não desenvolveu a capacidade de transferir algumas competências já identificadas, como por exemplo, o conhecimento que possui na área de computadores de grande porte (mainframe).

Não se verificou, nos dois casos analisados, uma relação direta entre a autonomia das subsidiárias e o aumento de sua importância estratégica (FROST; BIRKINSHAW; ENSIGN, 2002). A autonomia de uma subsidiária tem mais sentido em um ambiente menos globalizado. Em setores mais globalizados, como o de TI, a subsidiária é forçada a abrir mão de certa autonomia na medida em que necessita se inserir na rede da corporação (integrando inovação, produção e distribuição).

Segundo afirmam Birkinshaw e Hood (1998), as três perspectivas determinismo ambiental, determinação da matriz, e escolha da subsidiária - interagem dinamicamente para determinar o papel e a evolução das subsidiárias. Observe-se que as variáveis que determinam o desenvolvimento do papel das subsidiárias em um dado momento podem ter efeitos distintos - ou mesmo nenhum - posteriormente. Assim, se, por um lado, a subsidiária brasileira pode vir a perder relevância estratégica devido ao aumento de custo ou à falta de inovação, por outro, a subsidiária indiana pode vir a enfrentar desafios diferentes, como o tamanho limitado de seu mercado interno.

A análise comparativa dos casos evidencia dois fatores que podem ser considerados essenciais para se entender a futura evolução das duas subsidiárias analisadas: (i) a capacidade e a qualidade da gestão e (ii) a visão estratégica das lideranças das subsidiárias.

A capacidade de gestão foi identificada como um diferencial determinante do desenvolvimento do papel das subsidiárias. A capacidade de gestão está associada à capacidade de executar planos nos tempos acordados e de entregar serviços no nível de qualidade pré-definido. Com relação à questão de visão estratégica da liderança, os executivos da subsidiária brasileira não associam o desenvolvimento dessa subsidiária ao aumento de responsabilidade internacional. Para eles, o aumento de importância da subsidiária está relacionado apenas ao aumento de faturamento e market-share local. Essa visão pode afetar negativamente a evolução das subsidiárias.

Este estudo levantou algumas questões que não puderam ser estudadas em profundidade nesta fase, mas que seriam bastante pertinentes para ser analisadas em trabalhos futuros, a começar pela comparação do desempenho entre exportação das subsidiárias estrangeiras localizadas no Brasil e empresas locais. Assim, seria possível verificar a influência das subsidiárias para posicionar o País como centro exportador. Outra área que merece ser estudada é a de políticas públicas para promover a inovação em países em desenvolvimento. Seria interessante a realização de uma pesquisa mais aprofundada sobre a efetividade das políticas utilizadas para estimular o desenvolvimento local. 
Outsourcing de TI e redefinição do papel da subsidiária: um estudo comparativo entre as subsidiárias brasileira e indiana de uma multinacional americana

\section{REFERÊNCIAS}

Arora, A.; Gambardella, A. (2005). The globalization of the software industry: perspectives and opportunities for developed and developing countries. Cambridge: MIT Press.

Bartlett, C., Ghoshal, S. (1989). Managing across borders: the transnational solution. Boston: Harvard Business School Press.

Birkinshaw, J. (1996). How multinational subsidiary mandates are gained and lost. Journal of International Business Studies, 27 (3), p. 467-496.

Birkinshaw, J. (1999). The determinants and consequences of subsidiary initiative in multinational corporations. Entrepreneurship: Theory and Practice, 24 (1), p. 9-36

Birkinshaw, J. (2001). Strategy and management in MNE subsidiaries. In: Rugman, A; Brewer, T. (Eds.). Oxford Handbook of International Business. Oxford: Oxford University Press.

Birkinshaw, J.; Hood, N. (1998). Multinational subsidiary evolution: Capability and charter change in foreign-owned subsidiary companies. The Academy of Management Review, 23 (4), p. 773-796.

Birkinshaw, J.; Hood, N.; Jonsson, S. (1998). Building firm-specific advantages in multinational corporations: The role of subsidiary initiative. Strategic Management Journal, 19 (3), p. 221-241.

Birkinshaw, J.; Morrison, A. (1995). Configurations of strategy and structure in subsidiaries of multinational corporations. Journal of International Business Studies, 26 (4), p. 729-754.

Bonoma, T. (1985). Case research in marketing: opportunities, problems, and a process. Journal of Marketing Research, 22 (May), p. 199-208,

Borini, F. M.; Oliveira Jr., M. M.; Guevara, A. J. H. (2004). O contexto competitivo nacional e a relevância estratégica das subsidiárias brasileiras de corporações multinacionais. In: XXVIII ENANPAD. Anais Eletrônicos.

Brazilian Association of Information Technology and Communication Companies (BRASSCOM) (2005). Desenvolvimento de uma agenda estratégica para o setor de IT offshore outsourcing”. Brasília.

Carmel, E.; Tjia, P. (2005). Offshoring information technology: sourcing and outsourcing to a global workforce. Cambridge: Cambridge University Press.

Corbett, M. (2004). The outsourcing revolution: Why it makes sense and how to do it right. Kaplan Professional.

D’cruz, J.R. (1986). Strategic Management of Subsidiaries. In: Etemad, H.; Dulude, L. S. (Eds.). Managing the Multinational Subsidiary: response to environment change and the host nation $R$ and $D$ policies. London: Croom Helm.

Eisenhardt, K. M. (1989). Building Theories From Case Study Research. Academy of 
Management Review, 14 (4), p. 532-550.

Farr, R. M. (1982). Interviewing: the social psychology of the inter-view. In: Fransella, F. (ed.) Psychology for Occupational Therapists. London: Macmillan, p. 151-170.

Ferdows, K. (1997). Making the most of Foreign Factories. Harvard Business Review, 75 (2), p. 73-88.

Frost, T.; Birkinshaw, J.; Ensign, P. (2002). Centers of excellence in multinational corporations. Strategic Management Journal, 23 (11), p. 997-1018.

Gartner (2005). Gartner on Outsourcing, Gartner Research, ID Number: G00131095.

Gartner (2008). Gartner on Outsourcing, Gartner Research, ID Number: G00164206.

Godoy, A. S. Introdução à pesquisa qualitativa e suas possibilidades. Revista de Administração de Empresas, 35 (2), p. 57-63.

Goode, W.J.; Hatt, P. K. (1973). Métodos em Pesquisa Social. 4.ed.. São Paulo: Editora Nacional.

Gottschalk, P.; Solli-sæther, H. (2006). Managing Successful IT Outsourcing Relationships. London: Idea Group Publishing.

Greenwood, E. (1973). Métodos Principales de Investigación Social Empírica. In: Metodologia de la Investigación Social. Buenos Aires: Paidos.

Gupta, A.; Govindarajan, V. (1991). Knowledge flows and the structure of control within multinational corporations. Academy of Management Review, 16 (4), 768-792.

Halinen, A.; Törnroos, J. (2005). Using case methods in the study of contemporary business networks. Journal of Business Research, 58 (9), p. 1285-1297.

Holm, U; Pedersen, T. (2000). The dilemma of centres of excellence - Contextual creation of knowledge versus global transfer of knowledge. Scandinavian Working Papers in Business Administration, No 8.

IDC. (2005). Brazil: Network Outsourcing and Management Services: Análise de Mercado. IDC Brasil

Jarillo, J. C.; Martinez, J. I. (1990). Different roles for subsidiaries: The case of multinational corporation in Spain. Strategic Management Journal, 11 (7), p. 501-512.

Jick, T. D. (1979). Mixing Qualitative and Quantitative Methods: Triangulation in Action. Administrative Science Quarterly, 24 (4), p. 602-611.

Krishnan, R.T. (2006). Subsidiary Initiative in Indian Software Subsidiaries of MNCs. Vikalpa, 31 (1), p. 61-71

Makino, S., Isobe, T., \& Chan, C.M. (2004). Does country matter? Strategic Management Journal, 25 (10), p. 1027-1043.

Miles, M. B; Huberman, M. (1984). Qualitative Data Analysis: A Sourcebook of New Methods. Newbury Park: Sage.

Governo Federal do Brasil. (2003). Diretrizes de política industrial, tecnológica e de comércio exterior. Disponível em: $<$ http://www.abdi.com.br/abdi_redesign/publicacao/engine.wsp?tmp.area=332>. Acesso 
em abr. 2008.

Paterson, S. L.; Brock, D. M. (2002). The Development of subsidiary-management research: review and theoretical analysis. International Business Review, 11 (2) p. 139163.

Porter, M. E. (1990). Competitive Advantage of Nations. New York: Free Press.

Rugman, A.; Verbeke, A. (2001). Subsidiary Specific Advantages in Multinational Enterprises. Strategic Management Journal, 22 (3), p. 237-250.

Sahay, S., Nicholson, B.; Krishna S. (2003). Global IT outsourcing: Software development across borders. Cambridge: Cambridge University Press.

Softex (2002). A indústria de software no Brasil 2002: Fortalecendo a economia do conhecimento. Campinas: SOFTEX.

Soy, S. K. (1997). The Case Study as a Research Method. University of Texas. Disponível em <http://www.gslis.utexas.edu? ssoy/useusers/1391d1b.htm> Acesso em ago.2005.

White, R. E.; Pointer, T. A. (1984). Strategies for Foreign-Owned Subsidiaries. Canada Business Quartely, 48 (4), p. 657-677.

Yin, R.. K. (2001). Estudo de Caso: Planejamento e Métodos. Porto Alegre: Bookman.

Zahra, A. S.; Gerard, G.; Dharwadkar, R. (2001). Entrepreneurship in the Multinational Corporation: The effects of corporate and local contexts. Conference Proceedings, Academy of Management, Toronto, Canada, Aug 4-9. 
Silva, M. A. da, Duarte, R. G., Castro, J. M. de, Araújo, A. R., 